\title{
PREFACE TO THE THIRD EDITION
}

IN THE course of time since Bibliography and Footnotes was first printed, many students, research workers, and librarians concerned with advising writers have commended the work as a concise and practical guide. Many, too, have requested "more illustrations" and "much more about government documents." The present revision offers additional information, with as little sacrifice of brevity as possible.

The fundamentals of bibliographical and footnote references to books and articles are treated with only slight changes from what was said in the second edition. This part of the work may be used separately, without reference to the full treatment of government documents, statute and case citations, or scientific references. For the benefit of those who are primarily interested in references to documents the fundamentals of document citation and their characteristic peculiarities are described in detail in the section on United States government documents. This section may be used or taught independently of such special categories of document reference as, for example, the United Nations. The expansion of government activities and government regulation in the social and economic fields, and the attendant increase in publications reporting and describing them, have made government documents one of our most abundant sources of printed information. Students are citing documents more than ever before, and no other class of printed materials presents so many confusing problems. The document sections in this manual are sufficiently detailed, and include a sufficient number of illustrations, to enable the student to apply the principles even when no special instruction has been given in class work.

Instructions for typing the final draft of a manuscript, and specimen thesis pages, have been added to meet the needs expressed by graduate students. It was not considered practical, however, to increase the size of this book further by inclusion of material on research methods; several dependable manuals are already available on general methods of assembling data, and others treat the special 
subject fields. Similarly, no attempt has been made to offer detailed rules of editorial practice, correct usage, proofreading, and the like, which are adequately presented in the manuals of style included in the "Selected List of References," pages 149-150. English composition and grammar, also, are considered to lie outside the scope of this work. And no attempt has been made to describe the varying usages in foreign languages, since it is assumed that if a student has a working knowledge of the principles of citation in English the application of these principles will be a matter of judgment, in whatever language the citation be made.

I am indebted to Joel F. Walters, Senior Editor, University of California Press, for his friendly interest and helpful suggestions during the preparation of this edition. Except for his sharp eye many faults might have otherwise appeared in print. Professor Wallace W. Douglas, Department of English, Northwestern University, has kindly given permission to use the title page and parts of his doctoral dissertation. The generous cooperation of Wyllis Wright, Librarian, and Juanita Terry, Reference Librarian, Williams College, has often allowed me to work conveniently in my home and also as far away as East Africa. Through the kindness of the Library staff of University College, Nairobi, Kenya, United Nations depository materials were there made available to me.

Williamstown, Massachusetts

M. L. H. R. 